\title{
Statins and Cognitive Functioning in the Elderly: A Population-Based Study
}

\author{
Julián Benito-León ${ }^{\mathrm{a}, \mathrm{b}, *}$, Elan D. Louis ${ }^{\mathrm{c}, \mathrm{d}, \mathrm{e}, \mathrm{f}}$, Saturio Vega ${ }^{\mathrm{g}}$ and Félix Bermejo-Pareja ${ }^{\mathrm{a}, \mathrm{b}}$ \\ ${ }^{a}$ The Department of Neurology, University Hospital "12 de Octubre”, Madrid, Spain \\ ${ }^{\mathrm{b}}$ Centro de Investigación Biomédica en Red sobre Enfermedades Neurodegenerativas (CIBERNED), Spain \\ ${ }^{\mathrm{c}}$ The G.H. Sergievsky Center, College of Physicians and Surgeons, Columbia University, New York, NY, USA \\ ${ }^{\mathrm{d}}$ Department of Neurology, College of Physicians and Surgeons, Columbia University, New York, NY, USA \\ 'Taub Institute for Research on Alzheimer's Disease and the Aging Brain, College of Physicians and Surgeons, \\ Columbia University, New York, NY, USA \\ ${ }_{\mathrm{f}}^{\mathrm{f}}$ Department of Epidemiology, Mailman School of Public Health, Columbia; University, New York, NY, USA \\ ${ }^{\mathrm{A}}$ Arévalo Health Center, Arévalo, Ávila, Spain
}

Accepted 19 February 2010

\begin{abstract}
In a 2009 Cochrane review, the authors concluded that there is good evidence that statins, given in late life to people at risk of vascular disease, have no effect in preventing Alzheimer's disease or dementia. A related issue, which remains unclear, is whether statins improve cognitive function. While some studies have shown a beneficial effect of statins on cognitive function, others have observed mild detrimental effects on cognition. Our aim was to assess cognitive function in community-dwelling elderly participants treated with statins compared with their untreated counterparts (i.e., controls) living in the same population. 137 population-dwelling participants who were receiving statins and 411 matched controls age $\geqslant 65$ years (median $=72$ years) in central Spain (the Neurological Disorders in Central Spain [NEDICES] study) underwent a neuropsychological assessment, including tests of global cognitive performance, frontal-executive function, verbal fluency, and memory. Median duration of statin treatment was 2 years. Of 137 participants receiving statins, $53(38.7 \%)$ were taking pravastatin, $38(27.7 \%)$ simvastatin, $37(27.0 \%)$ lovastatin, $6(4.4 \%)$ fluvastatin, and $3(2.2 \%)$ atorvastatin. Although initial univariate analyses indicated some differences, after adjusting for age, gender, education, depressive symptoms, premorbid intelligence, medications that potentially affect cognitive function, and blood cholesterol levels, statin users and controls performed similarly on all neuropsychological tests. In this population-based sample, elderly participants treated with statins and untreated controls performed similarly in all tested cognitive areas. These results do not support a positive benefit of statins on cognition.
\end{abstract}

Keywords: Cognitive function, elderly, epidemiology, statins

\section{INTRODUCTION}

The identification of modifiable risk factors for neurodegenerative diseases has important implications in terms of slowing or halting the progression of those diseases. Recent interest in 3-hydroxy-3methylglutaryl coenzyme A (HMG-CoA) reductase in-

* Correspondence to: Dr. Julián Benito-León, Avda. de la Constitución 73, portal 3, $7^{\circ}$ Izquierda, E-28821 Coslada, Madrid, Spain. E-mail: jbenitol@meditex.es. hibitors ("statins") has been sparked by the notion that these medications, which act via a cholesteroldependent mechanism, might reduce the production of amyloid- $\beta$ peptide, the major constituent of senile plaques, and, hence, the risk of developing Alzheimer's disease (AD) [1]. Indeed, a growing literature, with mixed results, has examined whether the use of these medications might lower the odds or risk of AD [2-4]. However, in a 2009 Cochrane review, the authors concluded that there is good evidence that statins given in late life to people at risk of vascular disease have no effect in preventing AD or dementia [5]. 
A related issue that remains unclear is whether statins might improve or affect cognitive function. On the one hand, statins were found to have beneficial effects on cognition in the non-demented elderly in three clinical trials [6-8] and in three community or populationbased surveys [9-11]. On the other hand, one randomized clinical trial has showed that statins may cause detrimental effects on cognitive performance in hypercholesterolemic adults aged 35-70 years [12]. In addition, cognitive function was unaffected in the elderly in two placebo-controlled trials of statin treatment [13, 14]. In all but three of these previous studies, participants were ascertained through clinical trials [9-11]. Therefore, selection factors may have influenced the findings of the clinical trials [6-8]. In addition, unmeasured confounders, including medications that potentially affect cognitive function (e.g., anxiolytics, stimulants, antipsychotics, antidepressants, antihistamines, or antiepileptics drugs) [15] may have influenced the results of previous clinical trials $[6,8,12,13]$ and community or population-based surveys outcomes [9-11]. We conducted a cross-sectional study of cognitive function in people treated with statins in a population-based elderly Spanish cohort. Our goal was to determine whether population-dwelling elderly individuals who were receiving statins have cognitive deficits or a better cognitive performance when compared with their counterparts living in the same population and not receiving statins. Our analyses adjusted for several confounders, including premorbid intelligence and medications with central nervous system effects [15].

\section{METHODS}

\section{Study population}

Data for these analyses were derived from the Neurological Disorders in Central Spain (NEDICES) study, a longitudinal, population-based survey of the prevalence, incidence, and determinants of major ageassociated conditions of the elderly, including Parkinson's disease, essential tremor, stroke, and dementia [16-25]. Detailed accounts of the study population and sampling methods have been published [23-25]. The study population was composed of elderly subjects, $\geqslant 65$ years old, living in three communities in central Spain (Las Margaritas, Lista, and Arévalo). The registered study population was 6,395 , but 481 people were ineligible (census issues, address errors, or death), leaving 5,914 eligible subjects, of whom 5,278 were enrolled. All procedures were approved by the ethical standards committees on human experimentation at the University Hospitals "12 de Octubre" (Madrid) and "La Princesa" (Madrid). Written (signed) informed consent was obtained from all participants upon enrollment.

\section{Study evaluation}

Detailed accounts of the study assessments have been published [23-25]. Face-to-face evaluations were performed at baseline (1994-1995) and then at follow-up (1997-1998). During the face-to-face evaluation, data were collected on demographics, current medications including statins and medications with central nervous system effects [15], medical conditions (e.g., diabetes mellitus, hypertension, heart disease), and the presence of depressive symptoms (the question, do you suffer from depression?). A short form of the questionnaire was mailed to subjects who refused, or were unavailable for face-to-face or telephone screening. This form assessed demographic characteristics, several neurological disorders (essential tremor, stroke, dementia, and parkinsonism), current medications, and the name of their family doctor. During the second (i.e., follow-up) evaluation (1997-1998), the same methods were used.

The data used in this study are from the second evaluation, which was carried out between 1997 and 1998, and included a neuropsychological test battery, which was implemented by psychologists, social workers, student nurses, and general physicians, all of whom had been trained by a senior clinical investigator with expertise in health sciences research (see acknowledgements, J.R-N.). In addition, in this second evaluation, blood samples for cholesterol determinations were drawn.

In the second evaluation, we identified all participants who were then being treated with statins on whom complete neuropsychological test data and cholesterol blood levels were available $(N=137)$. These participants were 1:3 frequency-matched with control subjects who were not receiving statins at the time of the second evaluation and who had complete neuropsychological test data and cholesterol blood levels. Frequency-matching was based on age (five year age categories), gender, educational category (none, can read and write, primary school, secondary school, and higher education), and intake of medications with central nervous system effects [15].

\section{Neuropsychological battery}

Many tools have been recommended for screening cognitive deficits in the elderly. Performance on these 


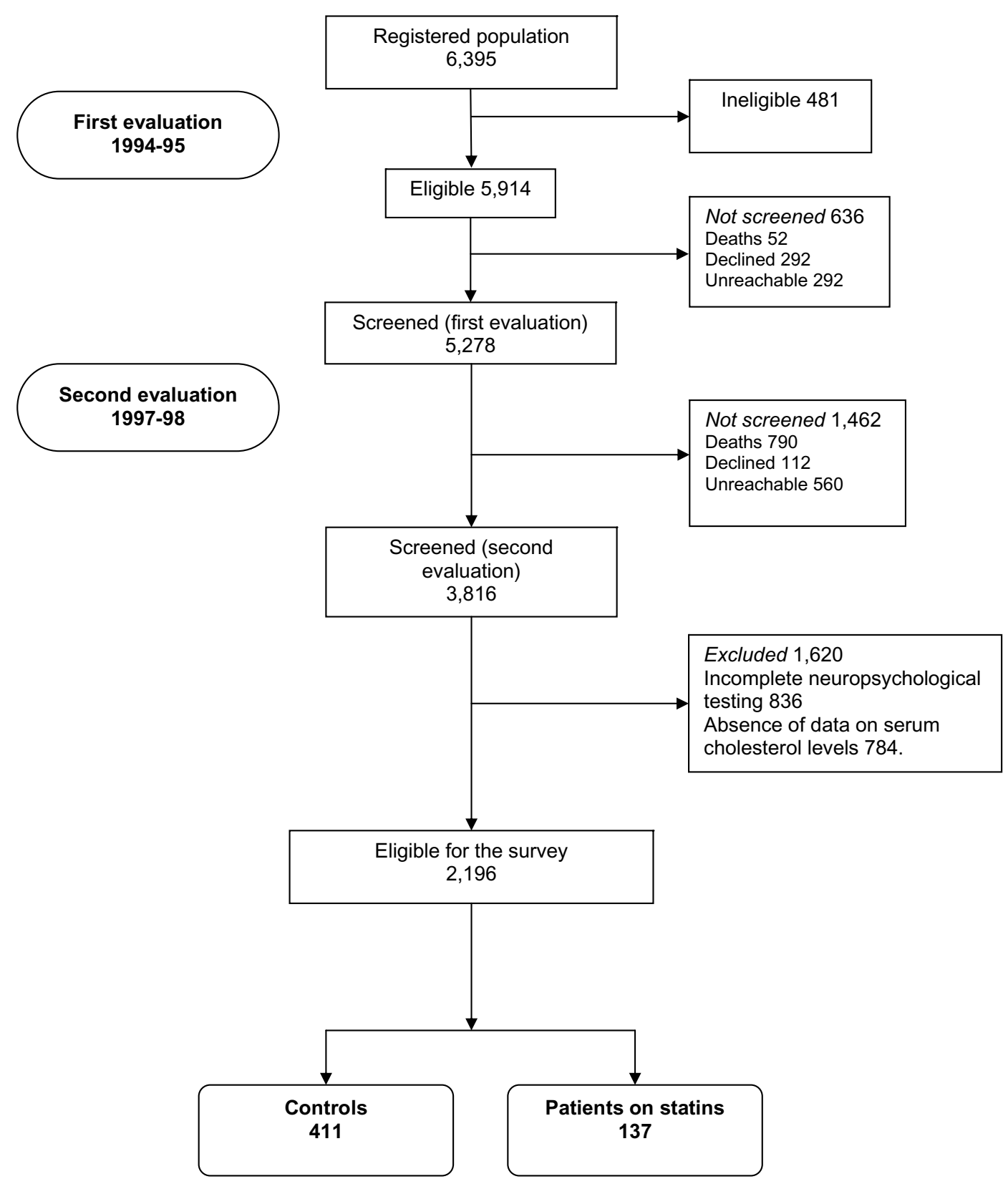

Fig. 1. Flow chart of the study.

tests can be influenced by age, educational level, ethnicity, and functional limitations [26,27]. Most screening tools have been developed in countries where secondary education is common. When used in populations with lower levels of education, there may be a high proportion of false positives [26,27]. In the second evaluation of the NEDICES study, $54.4 \%$ of the 3,816 screened subjects (Fig. 1) were either illiterate or could only read and write. We designed a neuropsychological battery that was more appropriate for our cohort; it was similar to that used in the "Aging in Leganés" study, a population-based survey carried out in Legan és city (central Spain) [26,27]. Our selection of tests was also influenced by their ease of use in an epidemiological setting. Neuropsychological tests were as follows:

\section{Global cognitive performance}

An expanded, 37-item version of the Mini-Mental 
State Examination (MMSE) was administered [28, 29]. More specifically, the 37-MMSE was adopted to Chilean, Maltese, and Spanish socio-cultural backgrounds and then validated against clinical diagnoses of dementia [21,22,30-33]. The 37-MMSE included all of the standard MMSE [30] items as well as three additional items: 1) an attention task, i.e., say 1, 3, 5, 7, 9 backwards; 2) a visual order, i.e., a man raising his arms; and 3) a simple construction task, i.e., copying two overlapping circles [21,22,30-33].

\section{Frontal executive function}

The easier form A of the Trail Making Test [34] was used. The subject linked, in successive order, the numbers 1 to 25, which were randomly distributed on a sheet of paper. Scoring was based on the time required to complete the task ( $>5 \mathrm{~min}$ versus $\leqslant 5 \mathrm{~min}$ ) and number of errors (higher scores indicate greater cognitive impairment) [34].

\section{Verbal fluency}

Subjects were asked to name as many different animals and fruits as they could in 60 seconds (lower scores indicate greater cognitive impairment) [35].

\section{Memory}

The six objects test was used [26,27], which consisted of the naming test that tested the ability to name line drawings of six common objects (range 0 [greater cognitive impairment] to 6); immediate free recall of the six objects (range 0 [greater cognitive impairment] to 6); and delayed free recall of the six objects $5 \mathrm{~min}$ later (range 0 [greater cognitive impairment] to 6). Also used was the story recall task [36], which required participants to listen to a brief narrative containing six informational bits. Their recall immediately after hearing the story (immediate logical memory) and after a 20-min delay (delayed logical memory) were assessed (range 0 [greater cognitive impairment] to 6) [36].

\section{Premorbid intelligence}

This was evaluated with the Word Accentuation Test, which assessed the ability to accentuate 30 infrequently used Spanish words (range 0 [greater impairment] to 30) [37].

\section{Statistical analyses}

Analyses were performed in SPSS (version 15.0). Demographic and clinical characteristics of cases and controls were compared using Student's t tests and chi square tests. None of the neuropsychological tests scores was normally distributed (KolmogorovSmirnov, $p<0.001$ ), even after log-transformation. Therefore, scores were compared using a non-parametric approach (Mann-Whitney test and Spearman's rho). Linear regression analyses were not possible because the neuropsychological tests scores were not normally distributed. Therefore, to assess the effects of possible confounders (age, gender, education, depressive symptoms, and medications that potentially affect cognitive function), we divided the neuropsychological tests scores into two strata (highest quartile scores vs. all other scores). Logistic regression analyses were then performed, thereby allowing us to assess the possible confounding effects of age, gender, education, depressive symptoms, premorbid intelligence, medications that potentially affect cognitive function, and blood cholesterol levels. In these models, the dependent variable was the highest quartile of each one of the neuropsychological tests scores (reference $=$ all other scores) and the independent variable was statin use vs. non-use. These analyses generated odds ratios (OR) with $95 \%$ confidence intervals (CI).

\section{RESULTS}

Of the 5,278 participants screened at baseline, 672 were lost to follow-up either because they declined ( $n=112)$ or were unreachable $(n=560)$, and 790 died before they were contacted the second time (Fig. 1). Of the remaining 3,816 , there were 173 participants who were taking statins and 3,643 who were not. We excluded 836 participants because they had incomplete neuropsychological assessments and 784 because of absence of data on blood cholesterol levels. Therefore, the eligible sample for the study consisted of 2,196 subjects (Fig. 1).

The group of 1,620 subjects who were not included in the study because they had an incomplete neuropsychological assessments or absence of data on blood cholesterol levels were older than those who were eligible for the study (mean $=76.4 \pm 6.7$ vs. $75.7 \pm$ 6.1 years, Student's t-test, $t=3,261, p=0.001$ ), less educated $\left(\chi_{(1)}^{2}=119.1, p<0.001\right)$ and a larger proportion were women $\left(60.1 \%\right.$ versus $57.3 \%, \chi^{2}=2.96$, $p=0.09$ ). The excluded and eligible participants also differed with respect to the proportion who were statin users (36 [2.2\% vs. $137[6.2 \%], \chi^{2}=34.75, p<$ 0.001). 
Table 1

Demographic and Clinical Characteristics of Participants Receiving Statins and Controls

\begin{tabular}{lccc}
\hline & On statins $(N=137)$ & Controls $(N=411)$ & Significance \\
\hline Age (years) & $73.4 \pm 4.4$ & $73.3 \pm 5.1$ & $0.83^{\mathrm{a}}$ \\
Gender (female) & $85(62.0)$ & $243(59.1)$ & $0.61^{\mathrm{b}}$ \\
Educational level & & $0.41^{\mathrm{b}}$ & \\
$\quad$ None & $7(5.1 \%)$ & $32(8.3 \%)$ & \\
$\quad$ Can read and write & $59(43.1 \%)$ & $149(36.3 \%)$ & \\
$\quad$ Primary school & $48(35.0 \%)$ & $156(38.0 \%)$ & \\
$\quad$ Secondary school or higher & $23(16.8 \%)$ & $72(17.5 \%)$ & \\
On medication with CNS effects & $31(22.6)$ & $91(22.1)$ & $0.91^{\mathrm{b}}$ \\
Diabetes mellitus* & $26(19.0)$ & $59(14.4)$ & $0.22^{\mathrm{b}}$ \\
Hypertension & $85(62.0)$ & $208(50.6)$ & $0.02^{\mathrm{b}}$ \\
Heart disease & $28(20.4)$ & $34(8.3)$ & $<0.001^{\mathrm{b}}$ \\
Dementia & $2(1.5 \%)$ & $9(2.2 \%)$ & $0.74^{\mathrm{b}}$ \\
Stroke & $8(5.8 \%)$ & $22(5.4 \%)$ & $0.83^{\mathrm{b}}$ \\
Current smoker & $12(8.9 \%)$ & $51(12.6 \%)$ & $0.28^{\mathrm{b}}$ \\
Current drinker & $48(35.6 \%)$ & $147(36.6 \%)$ & $0.92^{\mathrm{b}}$ \\
Subjective memory complaints* & $57(42.9)$ & $171(43.1)$ & $1.0^{\mathrm{b}}$ \\
Depressive symptoms & $33(24.1)$ & $79(19.2)$ & $0.22^{\mathrm{b}}$ \\
Body mass index (kg/m $\left.{ }^{2}\right)^{*}$ & $28.1 \pm 4.7$ & $27.8 \pm 4.4$ & $0.52^{\mathrm{a}}$ \\
Serum cholesterol levels (mmol/L) & $4.4 \pm 0.9$ & $4.3 \pm 0.7$ & $0.15^{\mathrm{a}}$ \\
\hline
\end{tabular}

a Student's t test; ${ }^{\mathrm{b}}$ Chi-square test; ${ }^{*}$ Data on some participants were missing.

Mean \pm standard deviation and frequency $(\%)$ are reported.

The 137 participants receiving statins and 411 frequency-matched controls were similar in most respects, with the exception of the prevalence of hypertension and heart diseases (Table 1). Median duration of statin treatment was 2 years. Of the 137 people receiving statins, $53(38.7 \%)$ were taking pravastatin, $38(27.7 \%)$ simvastatin, $37(27.0 \%)$ lovastatin, $6(4.4 \%)$ fluvastatin, and $3(2.2 \%)$ atorvastatin. The median statin dose was of $20 \mathrm{mg}$ (range 10 to $40 \mathrm{mg}$ ).

In our controls, we examined whether neuropsychological test scores (esp. 37-MMSE) were associated with potential confounding variables. The 37-MMSE was correlated with age $\left(\mathrm{r}_{S}=-0.297, p<0.001\right)$, gender (mean $\pm \mathrm{SD}$ [median] $=31.3 \pm 5.5$ [33] in men vs. $29.5 \pm 4.8$ [30] in women, Mann-Whitney $\mathrm{U}$ test, $p=0.001)$, educational category $\left(\mathrm{r}_{S}=0.33\right.$, $p<0.001)$, subjective depressive symptoms $(28.3 \pm$ 4.9 [29] in those who responded "yes" vs. $30.7 \pm$ 5.1 [32] in those who responded "no", Mann-Whitney $\mathrm{U}$ test, $p<0.001)$. The 37-MMSE was marginally correlated with medications that could affect cognition (mean $\pm \mathrm{SD}[$ median] $=29.4 \pm 5.3[30]$ in those taking a medication vs. $30.4 \pm 5.0$ [31] in those who do not take a medication, Mann-Whitney $\mathrm{U}$ test, $p=0.12$ ).

Statin users versus non-users differed with respect to verbal fluency tests, naming, immediate free recall, and premorbid intelligence; performance on the 37-MMSE was marginally different $(p=0.062)$ with the controls performing more poorly (Table 2 ). However, in a regression analysis that adjusted for age in years, gender, educational category, premorbid intelligence, intake of any medication that can affect cognition (one variable coded as yes vs. no), depressive symptoms (coded as yes vs. no), and blood cholesterol levels, we found that exposure category (statin use vs. control) was associated with none of the highest quartiles of neuropsychological tests scores (Table 3 ). In participants receiving statins, treatment duration was not correlated with any neuropsychological test score results (data not shown).

\section{DISCUSSION}

We examined a population-dwelling sample of older people in central Spain who were taking statins. After adjusting for potential confounders, including medications with central nervous effects and premorbid intelligence, participants taking statins did not differ from their untreated counterparts in the performance of formal neuropsychological tests. Our results are in line with two placebo-controlled trials of statin treatment in the elderly $[13,14]$. Antidepressants, anxiolytics, stimulants, antihypertensives, antiepileptics, or antihistamines can affect psychomotor functioning, concentration, and memory [15]. Hence, it is important to adjust for the use of these types of medications when assessing cognition using a neuropsychological test battery [15]. We also adjusted for serum total cholesterol level, since there is evidence that cholesterol may affect cognition; higher midlife serum total cholesterol 
Table 2

Neuropsychological Tests Performance of Participants Receiving Statins and Controls

\begin{tabular}{|c|c|c|c|c|}
\hline Cognitive domain & Neuropsychological tests & People receiving statins & Controls & $p$ value \\
\hline Global Cognitive Performance & 37-MMSE (range $=0-37$ ) & $31.0 \pm 5.2(33)$ & $30.2 \pm 5.1(31)$ & $0.062^{\mathrm{a}}$ \\
\hline \multirow{2}{*}{ Frontal Executive Function } & Trail making test-A (number of errors) & $1.2 \pm 3.8(0)$ & $1.7 \pm 7.6(0)$ & $0.140^{\mathrm{a}}$ \\
\hline & Trail making test-A (time to complete it) $>5$ minutes & $14(11.3 \%)$ & $34(9.5 \%)$ & $0.602^{\mathrm{b}}$ \\
\hline \multirow{2}{*}{ Verbal Fluency } & Verbal fluency (animals) & $14.8 \pm 5.0(15)$ & $13.4 \pm 4.7(13)$ & $0.002^{\mathrm{a}}$ \\
\hline & Verbal fluency (fruits) & $11.4 \pm 3.4(11)$ & $10.6 \pm 3.4(10)$ & $0.014^{\mathrm{a}}$ \\
\hline \multirow[t]{5}{*}{ Memory } & Naming test (score 0-6) & $5.9 \pm 0.5(6)$ & $5.7 \pm 0.8(6)$ & $0.040^{\mathrm{a}}$ \\
\hline & Immediate free recall (score $0-6$ ) & $4.6 \pm 1.1(5)$ & $4.3 \pm 1.2(4)$ & $0.013^{\mathrm{a}}$ \\
\hline & Delayed free recall (score 0-6) & $4.3 \pm 1.5(5)$ & $4.1 \pm 1.6(4)$ & $0.338^{\mathrm{a}}$ \\
\hline & Immediate logical memory (score 0-6) & $3.9 \pm 1.7(5)$ & $4.4 \pm 1.5(5)$ & $0.149^{\mathrm{a}}$ \\
\hline & Delayed logical memory (score 0-6) & $4.1 \pm 2.0(5)$ & $3.7 \pm 2.1(4)$ & $0.050^{\mathrm{a}}$ \\
\hline Premorbid Intelligence & Word Accentuation Test (score 0-30) & $18.5 \pm 9.1(20)$ & $16.4 \pm 8.7(16)$ & $0.030^{\mathfrak{a}}$ \\
\hline
\end{tabular}

Results are means \pm standard deviations and (medians). MMSE $=$ Mini-Mental State Examination. ${ }^{\mathrm{a}}$ Mann-Whitney $U$ test. ${ }^{\mathrm{b}} \mathrm{Chi}-\mathrm{square}$.

Table 3

Highest Quartile of Each One of the Neuropsychological Tests Scores and Odds of Being Treated with Statins

\begin{tabular}{lccccccc}
\hline Neuropsychological tests & \multicolumn{3}{c}{ Unadjusted } & & & \multicolumn{2}{c}{ Adjusted $^{* *}$} \\
\cline { 2 - 4 } \cline { 5 - 7 } & Odds ratio & $95 \%$ CI & p value & & Odds ratio & 95\% CI & p value \\
\hline highest quartile of 37-MMSE & 1.0 & $0.7-1.6$ & 0.82 & & 1.1 & $0.6-2.0$ & 0.66 \\
Highest quartile of Trail making test-A (errors) & 0.8 & $0.5-1.4$ & 0.47 & & 0.8 & $0.4-1.4$ & 0.40 \\
Trail making test-A (time to complete it) & 1.2 & $0.6-2.3$ & 0.57 & & 1.7 & $0.8-3.8$ & 0.17 \\
Highest quartile of verbal fluency (animals) & 1.8 & $1.1-2.7$ & 0.008 & & 1.7 & $0.9-2.9$ & 0.06 \\
Highest quartile of verbal fluency (fruits) & 1.6 & $1.1-2.5$ & 0.02 & & 1.3 & $0.8-2.3$ & 0.31 \\
Highest quartile of naming test & 2.0 & $1.0-4.1$ & 0.045 & & 1.5 & $0.6-3.4$ & 0.37 \\
Highest quartile of immediate free recall & 1.3 & $0.8-2.1$ & 0.27 & & 1.4 & $0.8-2.6$ & 0.21 \\
Highest quartile of delayed free recall & 0.9 & $0.5-1.5$ & 0.73 & & 1.0 & $0.5-2.0$ & 0.90 \\
Highest quartile of immediate logical memory & 1.2 & $0.8-1.8$ & 0.40 & & 1.2 & $0.7-2.0$ & 0.45 \\
Highest quartile of delayed logical memory & 1.3 & $0.8-2.0$ & 0.23 & & 1.1 & $0.7-1.9$ & 0.61 \\
\hline
\end{tabular}

* In this model, the dependent variable was $>5$ minutes to complete the Trail Making Test (reference $<5$ minutes).

** Adjusted for age, gender, educational category (none, can read and write, primary school, secondary school and higher education), premorbid intelligence, intake of medications that potentially affect cognition function, depressive symptoms, and blood cholesterol levels.

may be associated with poorer late-life cognition, but decreasing serum total cholesterol after midlife may reflect poorer cognitive status [11]. Furthermore, in oldest old $(\geqslant 85$ years) nondemented noncarriers of the APOE4 allele, high cholesterol may be associated with better memory function [38].

Better performance on neuropsychological tests has been observed in prior clinical trials and community or population-based surveys. In the Heart and Estrogen/progestin Replacement Study of 1,037 postmenopausal women $<80$ years with coronary heart disease the Modified MMSE (scores ranging from 0 to 100) was administered after 4 years of follow-up. Compared with nonusers, statin users had higher mean \pm standard deviations Modified MMSE scores (vs. 93.7 \pm 6.1 vs. $92.7 \pm 7.1, p=0.02$ ) [6]. Furthermore, in a case-control study, 55 people age 40 or older treated with atorvastatin scored significantly better than the placebo group in several cognitive areas, including attention, psychomotor speed, mental flexibility, working memory, and memory retrieval [7]. In line with this, in another study, improvement in verbal fluen- cy and working memory were observed in the simvastatin treated group (29 asymptomatic middle-aged adult children of people with AD) compared to 28 controls [8]. In a prospective community-based study of 3,334 people age 65 or older study, the rate of decline on the Modified MMSE was 0.48 point/year less in those taking statins compared with the untreated group for whom treatment was recommended ( $p=0.069$ ) and 0.49 point/year less in statin users compared with the group in whom lipid-lowering treatment was not recommended ( $p=0.009$ ) [9]. In addition, a recent prospective community-based study of 1,146 African Americans aged 70 and older living in Indianapolis, Indiana, showed that baseline statin use was associated with less dementia $(\mathrm{OR}=0.32 ; p=0.07)$ and less cognitive decline $(p=0.02)$ [10]. Finally, a longitudinal population-based study of 1,382 middle-aged adults reexamined after an average follow-up of 21 years also suggested that statins might be beneficial for cognition in nondemented elderly [11]. In contrast, statins use has been associated with more cognitive impairment. Thus, in a randomized trial comprising 308 hyperc- 
holesterolemic adults between 35 and 70 years of age, minor decrements in cognitive function were observed with statins [12]. The mechanism by which statins may affect cognitive function is not known. The authors argued that there are several possibilities, including that statins might alter neuronal function through effects on brain cholesterol metabolism, ubiquinone, protein prenylation, vitamin E, and omega-3 fatty acids [12].

Our study has limitations. First, the cross-sectional sample does not allow us to examine causation. Second, we only included people aged 65 and older; the NEDICES study, in which this study was nested, was a study of the elderly (age 65 years and older). However, the study of the relationship statins-cognition in elderly people is of special interest, since prevalence and incidence of cognitive problems is higher in this age group anyway [21,22]. Third, we used a relatively restricted neuropsychological test battery that did not sample all cognitive domains. Our battery was designed to meet the constraints of an epidemiological study in a cohort with lower levels of education and our selection of tests was also influenced by their ease of use in a population sample of approximately 4,000 elderly subjects in an epidemiological setting [26,27]. Finally, we assessed depressive symptoms by self-report and, although our screening question was modeled on a question that correctly diagnosed depression in $85.4 \%$ of participants [39], we may have under-ascertained depression. However, based on a validation study in which we showed a high level of agreement between the data generated from this screening question and a more detailed in-person psychiatric assessment [40], we think that such misclassification errors were likely to be low.

This study also has several strengths. We attempted to adjust for the effects of many potential confounders. Finally, the study was population-based, allowing us to assess a group of people unselected (unlike clinical trials) for treatment with statins.

\section{ACKNOWLEDGMENTS}

The authors gratefully acknowledge the vital help of the other members of the NEDICES Study Group: C. Rodríguez, R. Trincado, J.M. Morales, R, Gabriel, A. Portera-Sánchez, A. Berbel, A. Martínez-Salio, J. Díaz-Guzmán, J. Olazarán, J. Pardo, J. Porta-Etessam, F. Pérez del Molino, M. Alonso, C. Gómez, C. Saiz, G. Fernández, P. Rodríguez and F. Sánchez-Sánchez. Finally, we also wish to express our sincere thanks to J. de Pedro-Cuesta and J. Almazán, the municipal authorities, family doctors, nurses, and the populations of Getafe, Lista, and Arévalo county. NEDICES was supported by the Spanish Health Research Agency and the Spanish Office of Science and Technology. Dr. Benito-León is supported by NIH R01 NS024859 from the National Institutes of Health, Bethesda, MD, USA. Dr. Louis is supported by R01 NS042859 and R01 NS039422 from the National Institutes of Health, Bethesda, MD.

Authors' disclosures available online (http://www.jalz.com/disclosures/view.php?id=344).

\section{REFERENCES}

[1] Höglund K, Blennow K (2007) Effect of HMG-CoA reductase inhibitors on beta-amyloid peptide levels: implications for Alzheimer's disease. CNS Drugs 21, 449-462.

[2] Xiong GL, Benson A, Doraiswamy PM (2005) Statins and cognition: what can we learn from existing randomized trials? CNS Spectr 10, 867-874.

[3] Whitfield JF (2006) Can statins put the brakes on Alzheimer's disease? Expert Opin Investig Drugs 15, 1479-1485.

[4] Rockwood K (2006) Epidemiological and clinical trials evidence about a preventive role for statins in Alzheimer's disease. Acta Neurol Scand Suppl 185, 71-77.

[5] McGuinness B, Craig D, Bullock R, Passmore P (2009) Statins for the prevention of dementia. Cochrane Database Syst Rev 2, CD003160.

[6] Yaffe K, Barrett-Connor E, Lin F, Grady D (2002) Serum lipoprotein levels, statin use, and cognitive function in older women. Arch Neurol 59, 378-384.

[7] Parale GP, Baheti NN, Kulkarni PM, Panchal NV (2006) Effects of atorvastatin on higher functions. Eur J Clin Pharmacol 62, 259-265.

[8] Carlsson CM, Gleason CE, Hess TM, Moreland KA, Blazel HM, Koscik RL, Schreiber NT, Johnson SC, Atwood CS, Puglielli L, Hermann BP, McBride PE, Stein JH, Sager MA, Asthana S (2008) Effects of simvastatin on cerebrospinal fluid biomarkers and cognition in middle-aged adults at risk for Alzheimer's disease. J Alzheimers Dis 13, 187-197.

[9] Bernick C, Katz R, Smith NL, Rapp S, Bhadelia R, Carlson M, Kuller L;Cardiovascular Health Study Collaborative Research Group (2005) Statins and cognitive function in the elderly: the Cardiovascular Health Study. Neurology 65, 1388-1394.

[10] Szwast SJ, Hendrie HC, Lane KA, Gao S, Taylor SE, Unverzagt F, Murrell J, Deeg M, Ogunniyi A, Farlow MR, Hall KS (2007) Association of statin use with cognitive decline in elderly African Americans. Neurology 69, 1873-1880.

[11] Solomon A, Kreholt I, Ngandu T, Wolozin B, Macdonald SW, Winblad B, Nissinen A, Tuomilehto J, Soininen H, Kivipelto M (2009) Serum total cholesterol, statins and cognition in non-demented elderly. Neurobiol Aging 30, 1006-1009.

[12] Muldoon MF, Ryan CM, Sereika SM, Flory JD, Manuck SB (2004) Randomized trial of the effects of simvastatin on cognitive functioning in hypercholesterolemic adults. Am J Med 117, 823-829.

[13] Santanello NC, Barber BL, Applegate WB, Elam J, Curtis C, Hunninghake DB, Gordon DJ (1997) Effect of pharmacologic 
lipid lowering on health-related quality of life in older persons: results from the Cholesterol Reduction in Seniors Program (CRISP) Pilot Study. J Am Geriatr Soc 45, 8-14.

[14] Shepherd J, Blauw GJ, Murphy MB, Bollen EL, Buckley BM, Cobbe SM, Ford I, Gaw A, Hyland M, Jukema JW, Kamper AM, Macfarlane PW, Meinders AE, Norrie J, Packard CJ, Perry IJ, Stott DJ, Sweeney BJ, Twomey C, Westendorp RG; PROSPER study group (2002) PROspective Study of Pravastatin in the Elderly at Risk. Pravastatin in elderly individuals at risk of vascular disease (PROSPER): a randomized controlled trial. Lancet 360, 1623-1630.

[15] Stein RA, Strickland TL (1998) A review of the neuropsychological effects of commonly used prescription medications. Arch Clin Neuropsychol 13, 259-284.

[16] Benito-León J, Bermejo-Pareja F, Rodríguez J, Molina JA, Gabriel R, Morales JM; Neurological Disorders in Central Spain (NEDICES) Study Group (2003) Prevalence of PD and other types of parkinsonism in three elderly populations of central Spain. Mov Disord 18, 267-274.

[17] Benito-León J, Bermejo-Pareja F, Morales-González JM, Porta-Etessam J, Trincado R, Vega S, Louis ED; Neurological Disorders in Central Spain (NEDICES) Study Group (2004) Incidence of Parkinson disease and parkinsonism in three elderly populations of central Spain. Neurology 62, 734-741.

[18] Benito-León J, Bermejo-Pareja F, Morales JM, Vega S, Molina JA (2003) Prevalence of essential tremor in three elderly populations of central Spain. Mov Disord 18, 389-394.

[19] Benito-León J, Bermejo-Pareja F, Louis ED; Neurological Disorders in Central Spain (NEDICES) Study Group (2005) Incidence of essential tremor in three elderly populations of central Spain. Neurology 64, 1721-1725.

[20] Díaz-Guzmán J, Bermejo-Pareja F, Benito-León J, Vega S, Gabriel R, Medrano MJ; Neurological Disorders in Central Spain (NEDICES) Study Group (2008) Prevalence of stroke and transient ischemic attack in three elderly populations of central Spain. Neuroepidemiology 30, 247-253.

[21] Bermejo-Pareja F, Benito-León J, Vega S, Olazarán J, de Toledo M, Díaz-Guzmán J, Sánchez-Sánchez F, Morales-González JM, Trincado R, Portera-Sánchez A, Román GC (2009) Consistency of Clinical Diagnosis of Dementia in NEDICES: A Population-Based Longitudinal Study in Spain. J Geriatr Psychiatry Neurol 22, 246-255.

[22] Bermejo-Pareja F, Benito-León J, Vega S, Medrano MJ, Román GC; Neurological Disorders in Central Spain (NEDICES) Study Group (2008) Incidence and subtypes of dementia in three elderly populations of central Spain. $\mathrm{J} \mathrm{Neu-}$ rol Sci 264, 63-72.

[23] Morales JM, Bermejo FP, Benito-León J, Rivera-Navarro J, Trincado R, Gabriel S R, Vega S; NEDICES Study Group (2004) Methods and demographic findings of the baseline survey of the NEDICES cohort: a door-to-door survey of neurological disorders in three communities from Central Spain. Public Health 118, 426-433.

[24] Bermejo-Pareja F, Benito-León J, Vega-Q S, Díaz-Guzmán J, Rivera-Navarro J, Molina JA, Olazarán-Rodríguez J, MoralesGonzález JM (2008) La cohorte de ancianos NEDICES. Metodología y principales hallazgos neurológicos. Rev Neurol 46, 416-423.

[25] Vega S, Benito-León J, Bermejo-Pareja F, Medrano MJ, VegaValderrama LM, Rodríguez C, Louis ED (2010) Several factors influenced attrition in a population-based elderly cohort: Neurological disorders in Central Spain Study. J Clin Epi- demiol 63, 215-222.

[26] Zunzunegui MV, Gutierrez Cuadra P, Beland F, Del Ser T, Wolfson C (2000) Development of simple cognitive function measures in a community dwelling population of elderly in Spain. Int J Geriatr Psychiatry 15, 130-140.

[27] De Yébenes MJ, Otero A, Zunzunegui MV, Rodríguez-Laso A, Sánchez-Sánchez F, Del Ser T (2003) Validation of a short cognitive tool for the screening of dementia in elderly people with low educational level. Int J Geriatr Psychiatry 18, 925 936.

[28] Baldereschi M, Meneghini F, Quiroga P, Albala C, Mamo J, Muscat P (2004) Cognitive versus functional screening for dementia across different countries: cross-cultural validation of the Mini-Mental State Examination (MMSE) and the Pfeffer activities questionnaire (PFAQ) against the standardised clinical diagnosis of dementia. Neurology $\mathbf{4 4}$ (Suppl 2), A365.

[29] Folstein MF, Folstein SE, McHugh PR (1975) "Mini-mental state". A practical method for grading the cognitive state of patients for the clinician. J Psychiatr Res 12, 189-198.

[30] Olazarán J, Trincado R, Bermejo F, Benito-León J, Díaz J, Vega S (2004) Selective memory impairment on an adapted Mini-Mental State Examination increases risk of future dementia. Int J Geriatr Psychiatry 19, 1173-1180.

[31] Benito-León J, Louis ED, Bermejo-Pareja F; Neurological Disorders in Central Spain Study Group (2006) Elderly-onset essential tremor is associated with dementia. Neurology $\mathbf{6 6}$, 1500-1505.

[32] Bermejo-Pareja F, Louis ED, Benito-León J; Neurological Disorders in Central Spain (NEDICES) Study Group (2007) Risk of incident dementia in essential tremor: a populationbased study. Mov Disord 22, 1573-1580.

[33] Benito-León J, Bermejo-Pareja F, Vega S, Louis ED (2009) Total daily sleep duration and the risk of dementia: a prospective population-based study. Eur J Neurol 16, 990-997.

[34] Greenlief CL, Margolis RB, Erker GJ (1985) Application of the Trail Making Test in differentiating neuropsychological impairment of elderly persons. Percept Mot Skills 61, 12831289.

[35] Rosen WG (1980) Verbal fluency in aging and dementia. $J$ Clin Neuropsychol 2, 135-146.

[36] Wechsler D (1987) Wechsler Memory Scale-Revised. San Antonio, TX: The Psychological Corporation.

[37] Del Ser T, González-Montalvo JI, Martínez-Espinosa S, Delgado-Villapalos C, Bermejo F (1997) Estimation of premorbid intelligence in Spanish people with the Word Accentuation Test and its application to the diagnosis of dementia. Brain $\operatorname{Cogn}$ 33, 343-356.

[38] West R, Beeri MS, Schmeidler J, Hannigan CM, Angelo G, Grossman HT, Rosendorff C, Silverman JM (2008) Better memory functioning associated with higher total and lowdensity lipoprotein cholesterol levels in very elderly subjects without the apolipoprotein e4 allele. Am J Geriatr Psychiatry 16, 781-785.

[39] Mahoney J, Drinka TJ, Abler R, Gunter-Hunt G, Matthews C, Gravenstein S, Carnes M (1994) Screening for depression: single question versus GDS. J Am Geriatr Soc 42, 1006-1008.

[40] Louis ED, Benito-León J, Bermejo-Pareja F; Neurological Disorders in Central Spain (NEDICES) Study Group (2007) Self-reported depression and anti-depressant medication use in essential tremor: cross-sectional and prospective analyses in a population-based study. Eur J Neurol 14, 1138-1146. 